RESEARCH PAPER RP1561

Part of Journal of Research of the National Bureau of Standards, Volume 31, October 1943

\title{
STRUCTURE OF THE WOOL FIBER AS REVEALED BY THE ELECTRON MICROSCOPE
}

\author{
By Charles W. Hock ${ }^{1}$ and Howard F. McMurdie
}

ABSTRACT

An investigation of the wool fiber with the electron microscope was undertaken in order to get more data on the structure of the fiber and its constituent cells, and to correlate this information with results previously obtained by other methods. Specimens were prepared for examination by various physical and chemical procedures.

Over a wide range of magnifications the cortical cells always showed a distinctly fibrous structure. Whereas with the optical microscope only fibrils were observed within the cortical cells, the higher resolving power of the electron microscope made possible the resolution of still finer microfibrils. The scale cells, on the other hand, showed little internal organization. This difference in structure between the fibrous cortex and the nonfibrous or amorphous cuticle is believed to be of fundamental importance in interpreting many of the properties of the fibers.

\section{CONTENTS}

Page

I. Introduction

II. Apparatus and materials_.

1. The electron microscope

2. Samples of wool

III. Preparation of specimens

IV. Results and diseussion

1. Structure of the scale cells _._.

2. Structure of the cortical cells

V. References_... 236

\section{INTRODUCTION}

Wool fibers are not simple homogeneous structures but consist of various parts and layers that become apparent under suitable conditions of observation. Thus a growing wool hair is found to have a bulbous root situated below the surface of the skin and a filamentous shaft that extends above the skin surface. The shaft, in turn, is made up of dead cellular units which are arranged in three layers - an outer layer of scales (cuticle), a middle region called the cortex, and a central core, or medulla. The medulla, which, in the finest grades of wool, is either very narrow or absent altogether, is not believed to contribute appreciably to the mechanical properties of the fibers, and attention accordingly has been directed largely to an understanding of the structure of the scale and cortical cells. The scales are restricted to a thin layer which constitutes the outer surface of the

${ }_{1}$ Research Associate at the National Bureau of Standards, representing the Textile Foundation. 
fiber, whereas the cortex, either in the form of a solid or a hollow cylinder, depending on the extent of medullation, makes up the bulk of the fiber. A more detailed discussion of the microscopy of wool may be found in publications by Kronacher and Lodemann [1], ${ }^{2}$ Von Bergen [2], Von Bergen and Kraus [3], Reumuth [4], Müller [5], Hock, Ramsey, and Harris [6], and others.

The principal chemical constituent of wool is keratin, a protein consisting essentially of long polypeptide chains connected laterally by disulfide cross-linkages $[7,8,9,10,11]$. Although both the cuticle and cortex appear to belong to this same general class of proteins, there is abundant evidence from various lines of investigation which indicates that there are, nevertheless, certain differences between them. For example, when wool is treated with enzymes the fibers are attacked first at their cut ends, where the enzymes have, presumably, easier access to the fiber. Prolongation of this treatment, moreover, causes the cortical cells to become separated from each other and ultimately released from the fiber, whereas the scales remain practically intact in the form of a hollow tube $[6,12]$. Similarly, treatment of wool with reagents that cause swelling, such as sodium sulfide, shows that the scales are, as a rule, more resistant than the cells of the cortex $[13,14]$. Likewise, it has been reported [15] that the passage of solutions of acid dyestuffs into the fiber is resisted by the cuticle. A consideration of staining and dyeing also reveals other differences between the scale and cortical layers. For example, when wool cells which have been separated by acids, alkalis, or enzymes, are treated with dyes such as methylene blue or orange II, only the cortical cells have any affinity for the stains $[16,17]$. In like manner the work of Royer and Nillson on dyed wool [18] shows that the ends of the fibers, which are not protected by scales, take up dye more rapidly than do intermediate parts of the fiber. This phenomenon is the basis of a number of tests for damage, in which the cortex colors only where previous injury to the scales allows entry of the test reagents $[19,20,21]$. A further difference between the scales and cortical cells is revealed by the Allwörden reaction, in which the scales, unlike the cells of the cortex, swell up into little sacs when the fibers are placed in a saturated aqueous solution of chlorine [22].

The most detailed information concerning the structure of the various types of wool cells is available as a result of investigations with the optical microscope. Using this technique, the principal difference between the cortical cells and the scales is the fibrous appearance of the former and the uniform or amorphous appearance of the latter-a difference which may be of fundamental importance. Since the dissimilarities in chemical composition of the cuticle and cortex are evidently slight $[1,17,23,24,25]$, it seems probable that the differences in behavior of these two regions may be dependent more on physical than on chemical differences. Accordingly, it was thought interesting to note whether dissimilarities in structure are still observable at the high magnifications obtainable with the electron microscope, and the present study was undertaken to get more data on the structure of the wool fiber and its constituent cells and to correlate this information with results previously obtained by other methods.

${ }^{2}$ Figures in brackets indicate the literature references at the end of the paper. 


\section{APPARATUS AND MATERIALS}

\section{THE ELECTRON MICROSCOPE}

The electron microscope used in this study was the Radio Corporation of America's type $B$. instrument, having electromagnetic lenses. Its construction and use, as well as that of electron microscopes in general, has already been discussed in various publications [26, 27]. It is important to recall, however, that the image produced by the electron microscope is the result of absorption and scattering of the electron beam, and that these effects are, in turn, a function of the density and thickness of the object. Thus the electron image is a result of differences in the amount and kind of matter traversed by the electrons and is not produced by differences in refractive index, as is usually the case in photomicrography.

Considera le caution must be exercised in interpreting electron micrographs. Since the instrument is evacuated during use, drying of the specimens ensues and this may bring about changes in structure, particularly in biological specimens. Furthermore, organic materials are sometimes disintegrated by the electrons, especially where thick sections absorb large amounts of electron energy. These, as well as other possible alterations which may occur during the preparation of the specimens for examination, should be borne clearly in mind.

\section{SAMPLES OF WOOL}

In order to have observations on a fairly representative number of wools, five different samples were used in the investigation. One sample of fine merino wool was the same as that used previously in this laboratory. It was purified by extractions with ethyl alcohol and with ether for 16 hours each, followed by washing with water at $40^{\circ} \mathrm{C}$. The remaining wools had been given commercial degreasing treatments and were used just as received.

\section{PREPARATION OF SPECIMENS}

For a satisfactory examination with the electron microscope, specimens should not be more than a few tenths of a micron thick. Unfortunately, the finest wool fibers do not even approach this limit, so that various means must be used to obtain sections suitable for examination. Inasmuch as the methods of preparation may bring about changes in the structure of the specimens themselves, it seemed likely that the best understanding of the wool cells could be achieved by the examination of specimens that had been prepared by a variety of chemical and physical procedures. In the present investigation, specimens were prepared by the following four methods.

1. Untreated ${ }^{3}$ and undamaged wool reacts slowly to enzymes, but it is unusually susceptible to attack if, for example, the disulfide cross-linkages have been ruptured by reduction with thioglycolic acid and then methylated to prevent reformation of the linkages [12]. After treatment with pepsin for several days to a week, cortical and scale cells are released from the wool fibers. For the present work, cells obtained by this procedure were washed repeatedly with distilled water until the suspension was neutral, whereupon a drop of the suspension was placed on the specimen holder of the microscope and

${ }^{3}$ In this discussion wool fibers that received no specific chemical treatments before being placed in
enzymes will be designated untreated wool, whereas the fibers that were reduced and methylated before enzymes will be designated untreated wool, whercas the fibers that
being subjected to the action of enzymes will be called treated wool. 
allowed to dry. The scales were less than 0.5 micron in thickness and hence satisfactory for examination with the electron microscope. The cortical cells were too thick to allow passage of the electrons except at their tapering ends, and accordingly observations were confined principally to these regions.

2. Another method for obtaining scales for examination with the electron microscope involved treating the fibers with acid. Wool fibers were placed either in concentrated sulfuric acid for several hours or in concentrated formic acid for several weeks. This treatment loosened the scales and caused them to bend away from the fiber so as to resemble warped shingles on a roof. By subsequent agitation of the acid-treated fibers in a small amount of water, many scales and fragments thereof were removed. The released scales were washed with distilled water until neutral, and then examined in the usual manner. Although it is recognized that the acid treatment probably brings about changes in the structure of the scales, it is interesting to note that scales treated in this way still form Allwörden sacs when they are placed in chlorine water [6].

3. Mechanical separation of the scales from the fibers was accomplished by the method of King [28]. After attaching a weight to the fiber to keep it taut, the fiber was drawn across the edge of an ordinary glass slide mounted horizontally. In this way thin slivers were scraped off, and these sometimes appeared to consist solely of scale material.

4. Another method for obtaining scales by mechanical action involved the use of a Wiley mill. In this machine the fibers are cut lengthwise into rather long pieces which are, of course, too large and thick for examination. However, as the fibers pass through the mill, pieces of scale material are also broken and chipped from the surface of the fibers, and these fragments are suitable for use. In the microscope the thin scales were easily distinguished from the thick and dense pieces of fiber. Also, satisfactory specimens of cortical material were prepared by triturating the coarse powder from the mill between two pieces of ground glass.

\section{RESULTS AND DISCUSSION}

\section{STRUCTURE OF THE SCALE CELLS}

Scales from five different samples of wool were examined at several magnifications. Although the structural pattern varied, depending on the differences in experimental technique, all the scales, regardless of the method of preparation or of the samples from which they came, showed certain similarities. For example, the margin of the distal part of the scale, i.e., the part away from the point of attachment and not covered by overlapping scales, was relatively thick and dense, and hence showed little evidence of a finer structure. The proximal end of the scale, on the other hand, was thin enough to allow passage of the electrons and thereby reveal details. Thus the scale as a whole is evidently wedge-shaped, decreasing in thickness from its distal to its proximal end.

The scales, unlike the cortical cells, show little internal organization even at the highest magnifications obtainable with the optical microscope. Usually this instrument shows clearly that the scales overlap in a manner comparable to that of shingles on a roof, but there is almost no indication of a pattern within the scales themselves 
(fig. 1). The higher resolving power of the electron microscope, however, does reveal a pattern in the scales released by certain procedures. For example, figure 2 is an electron micrograph of part of a scale which had been prepared in exactly the same way as the scales shown in figure 1. The greater detail of the electron micrograph is evident, the scales appearing rather mottled, with less dense areas scattered throughout the denser regions. The less dense areas were irregular in shape, and varied in size up to about 1 micron. Generally speaking, all the scales separated from the fibers by chemical action had this mottled appearance. Specimens prepared by identical procedures did not, however, always have exactly the same appearance. Thus, although the scales obtained by treatment with sulfuric acid usually had a typical mottled appearance (fig. $3, A$ ), occasionally they exhibited a more porous or vesiculate pattern (fig. $3, B$ ). Likewise, the scales released by the action of untreated wool with pepsin often had the typical appearance of chemically released scales (fig. $4, A)$. Frequently, however, they underwent disintegration by the electrons, and then appeared as in figure $4, B$.

Mechanically removed scales showed less structure than those separated by chemical techniques. At magnifications of only several thousand times they appeared uniform, with little indication of a finer structure. Sometimes at higher magnifications a faint pattern was discernible (fig. $5, A$ ), but usually they still appeared structureless (fig. $5, B$ ). For a number of reasons it seems likely that the relatively uniform and amorphous appearance of these scales approaches more closely the true structure than that observed in chemically released specimens. In the first place, mechanical action would seem to be less drastic than that of chemicals. Probably more significant, however, is the fact that indirect evidence from other lines of investigation suggest a type of structure with which that observed in the mechanically removed specimens is in agreement. For example, observations with the polarizing microscope reveal that, unlike the cortical cells, which are anisotropic, the scales have little if any birefringence [6]. Similarly, X-ray data by Astbury and Street [29] show that the X-ray spectrum of the cuticle, especially in the stretched condition, differs from that of the whole fiber, and suggests a more or less random orientation in the former. The stable nature of the scale material to dyes, swelling agents, enzymes, and many other reagents, has already been pointed, and is, likewise, compatible with the present observations.

\section{STRUCTURE OF THE CORTICAL CELLS}

The examination of cortical cells with the electron microscope confirmed and extended the results previously obtained with the optical microscope. With the latter instrument it has been shown that cortical cells are spindle-shaped and that they have a striated appearance, except for a granular nucleus (fig. $6, A$ ). That the cells are fundamentally of fibrous structure, as indicted by their striated appearance, can be verified by dissecting single cortical cells with microneedles, whereupon numerous fibrils can be separated [6]. Between crossed nicols the fibrillate part of the cortical cell appears birefringent, whereas the granular nucleus does not (fig. $6, B$ ).

Because of their size, observations with the electron microscope of the cortical cells released by pepsin were confined principally to their thin and tapering ends. But there are good reasons for believing that, except for the nucleus, they have a similar structure throughout. It 
was found that over a wide range of magnifications the fibrous nature of these cells was still evident (figs. 7 and 8). However, whereas only fibrils were observed with the optical microscope, the electron microscope resolved still finer filaments, which, in the present investigation, will be called microfibrils. Zahn $[30,31]$ has similarly distinguished between fibrils and microfibrils in cortical cells. Figure 7, $B$ shows the end of a cortical cell that has become frayed during preparation for examination. The separation of the fibrils (about 1 micron in width) from each other and their subdivision into microfibrils is also evident. Figure 8 represents part of another cortical cell at a higher magnification and in greater detail. The micrograph shows, essentially, parts of two fibrils, each made up of microfibrils and each connected to the other by additional microfibrils. The microfibrils, like the fibrils, appear not to be constant in width but to vary from a few hundred to about a thousand angstroms. Although the microfibrils are roughly parallel to the long axis of the cell, they do not present a picture comparable to a pile of matches in parallel alinement. They are observed, rather, to coalesce, so that apparent spaces of various sizes up to several tenths of a micron are formed between them. Adjacent fibrils are connected by other microfibrils which have a much looser texture. In other words, there are more microfibrils per unit area in the dense regions (fibrils) than in the less dense regions (interfibrillar regions) of the cortical cell.

The structural details revealed by the electron microscope make possible a clearer interpretation of previously observed phenomena. It seems likely, for example, that when cortical cells are dissected by means of microneedles, the needles first penetrate the interfibrillar regions, where the microfibrils are more easily disrupted than in the compact fibrils. Upon further manipulation, the interfibrillar regions apparently are torn longitudinally, thereby separating the fibrils. Also, as previously pointed out, the cortical cells are birefringent in the polarizing microscope (fig. $6, B$ ). They are not, however, uniformly bright, but show alternate striations of high and low birefringence which appear to correspond to the fibrils and interfibrillar regions. From the present work with the electron micrsocope the fibrils might be expected to show greater brightness between crossed nicols because of the greater compactness of their microfibrils as compared with those in the interfibrillar regions. It should be borne in mind, however, that the light areas recorded on the micrographs, and which are especially abundant in the interfibrillar regions, do not necessarily indicate open spaces, but may only indicate areas which contain a material that is less dense than the surrounding microfibrils.

Upon examining specimens from reduced and methylated wool in the optical microscope, before and after their exposure to the electrons, there was no evidence that the cortical cells had been adversely affected by the electrons. Similarly, micrographs taken with the first flow of electrons through a specimen did not appear to differ from subsequent micrographs taken after longer bombardment. The behavior of cells from wool which had not been reduced was quite different. Just as soon as the beam of electrons struck these specimens, pronounced changes in structure occurred. The cells literally exploded and assumed a characteristic appearance (fig. 9). In the optical microscope the bombarded cells looked dark, charred, and distorted. This behavior, which is not uncommon with thick sections of organic 
Journal of Research of the National Bureau of Standards

Research Paper 1561

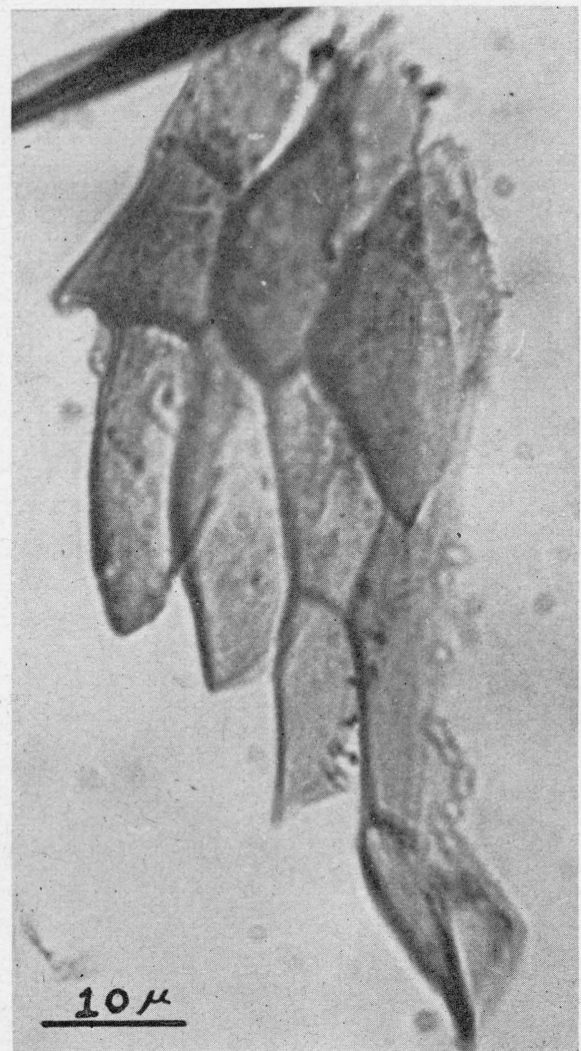

FIGURE 1.-Group of scales released by the action of pepsin on treated wool fibers. Stained with orange II. Photomicrograph, $\times 1,500$. 


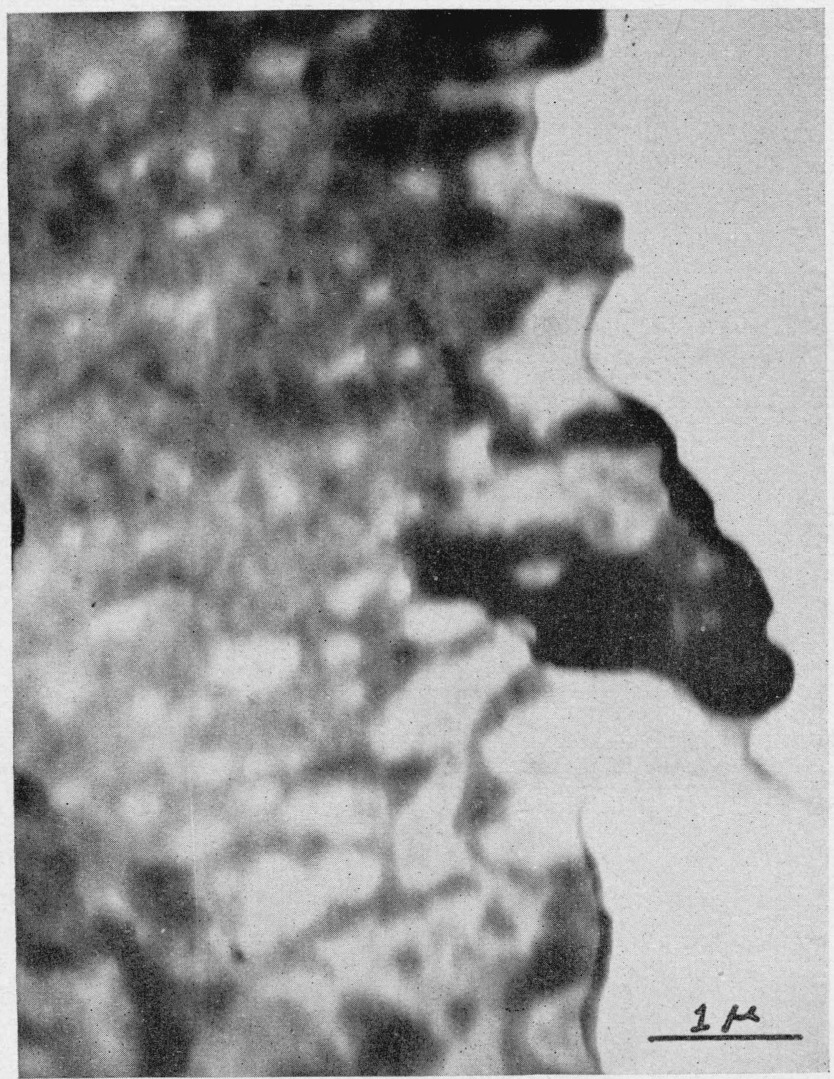

Figure 2.- Part of a scale, released from treated wool by pepsin, showing its - mottled appearance and fimbriate margin.

Electron micrograph, $\times 16,000$. 


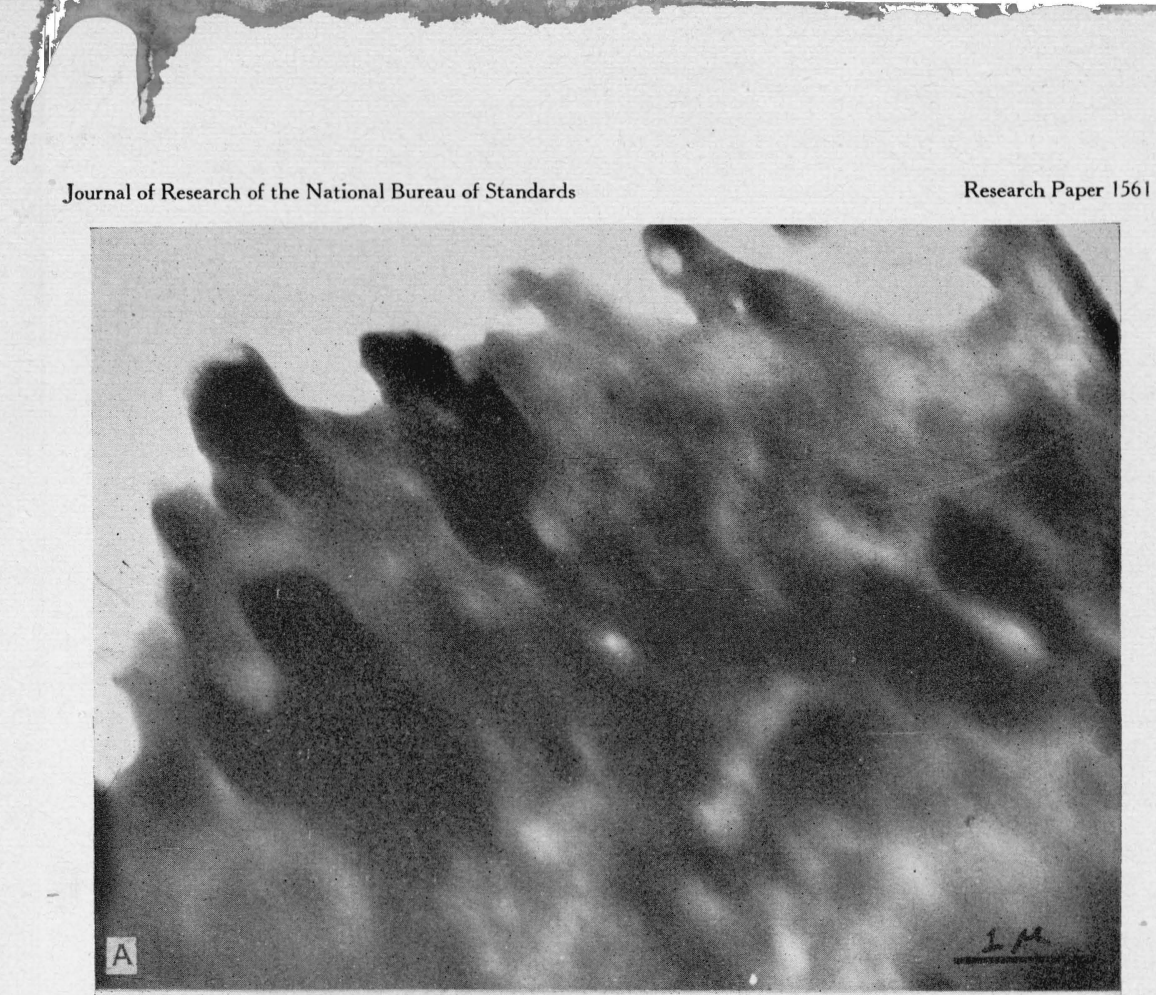

ournal of Research of the National Bureau of Standards

Research Paper 156

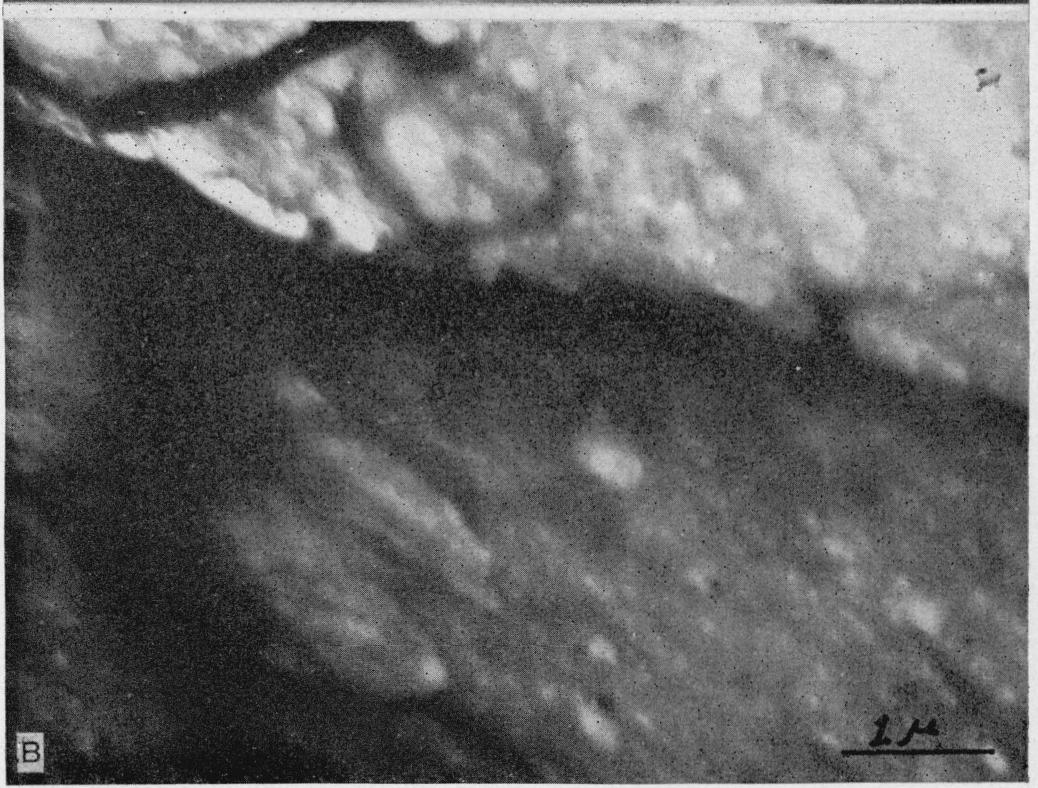

FIGURE 3.-Scales obtained from wool by treatment with sulfuric acid.

$A$, Proximal end of scale, having a mottled appearance. Electron micrograph, $\times 14,500$. B, Parts of several adjoining scales, showing a vesiculate structure. Electron micrograph, $\times 15,500$, 


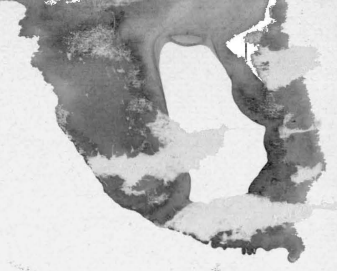

Journal of Research of the National Bureau of Standards:

Research Paper 1561
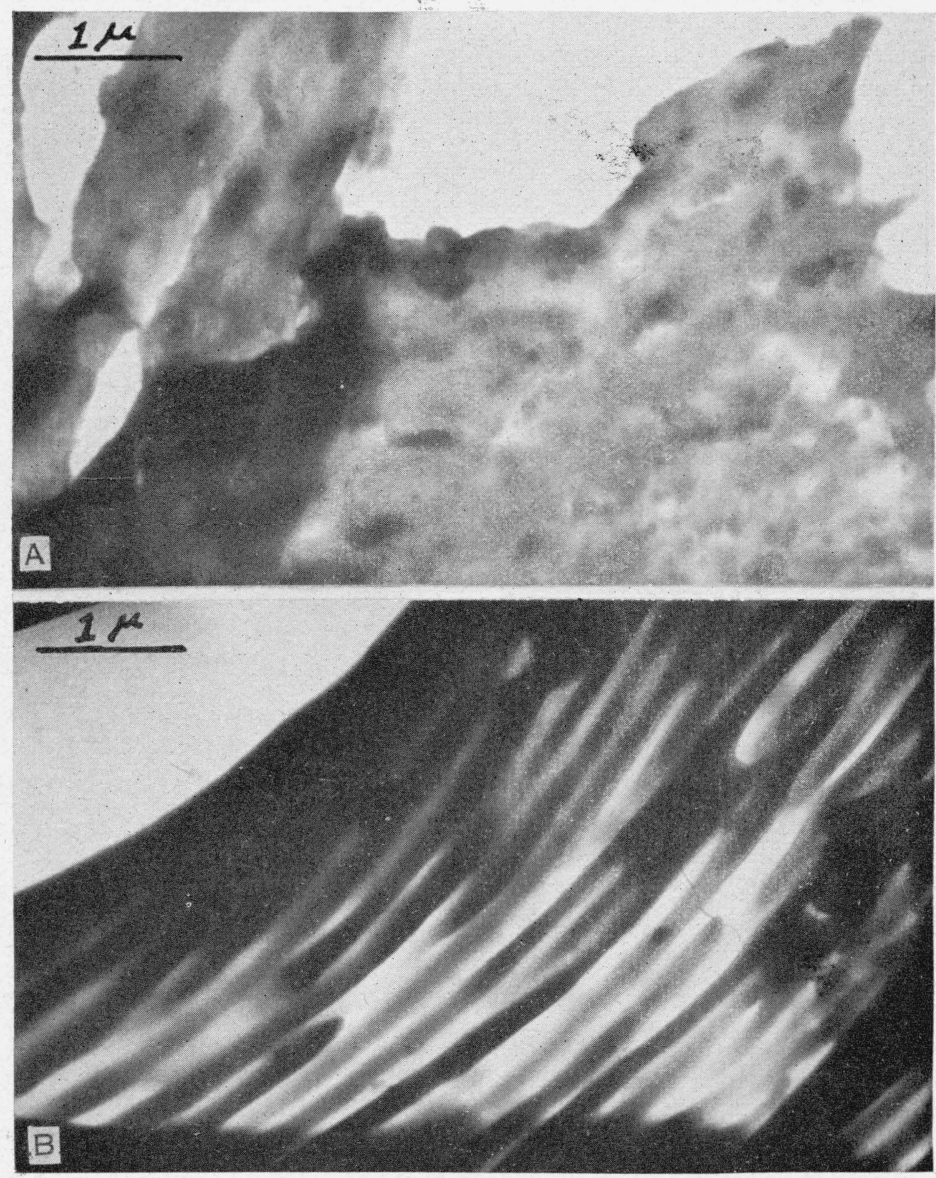

Figure 4.-Scales released from untreated wool by pepsin.

$A$, Part of scale, showing a mottled appearance. $B$, Part of scale which has undergone disintegration by the electrons. Electron mierograph, $\times 15,500$. 


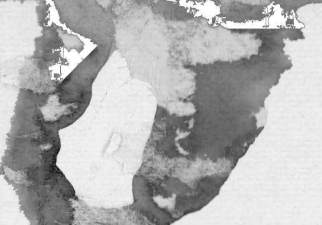

ournal of Research of the National Bureau of Standards

Research Paper 1561

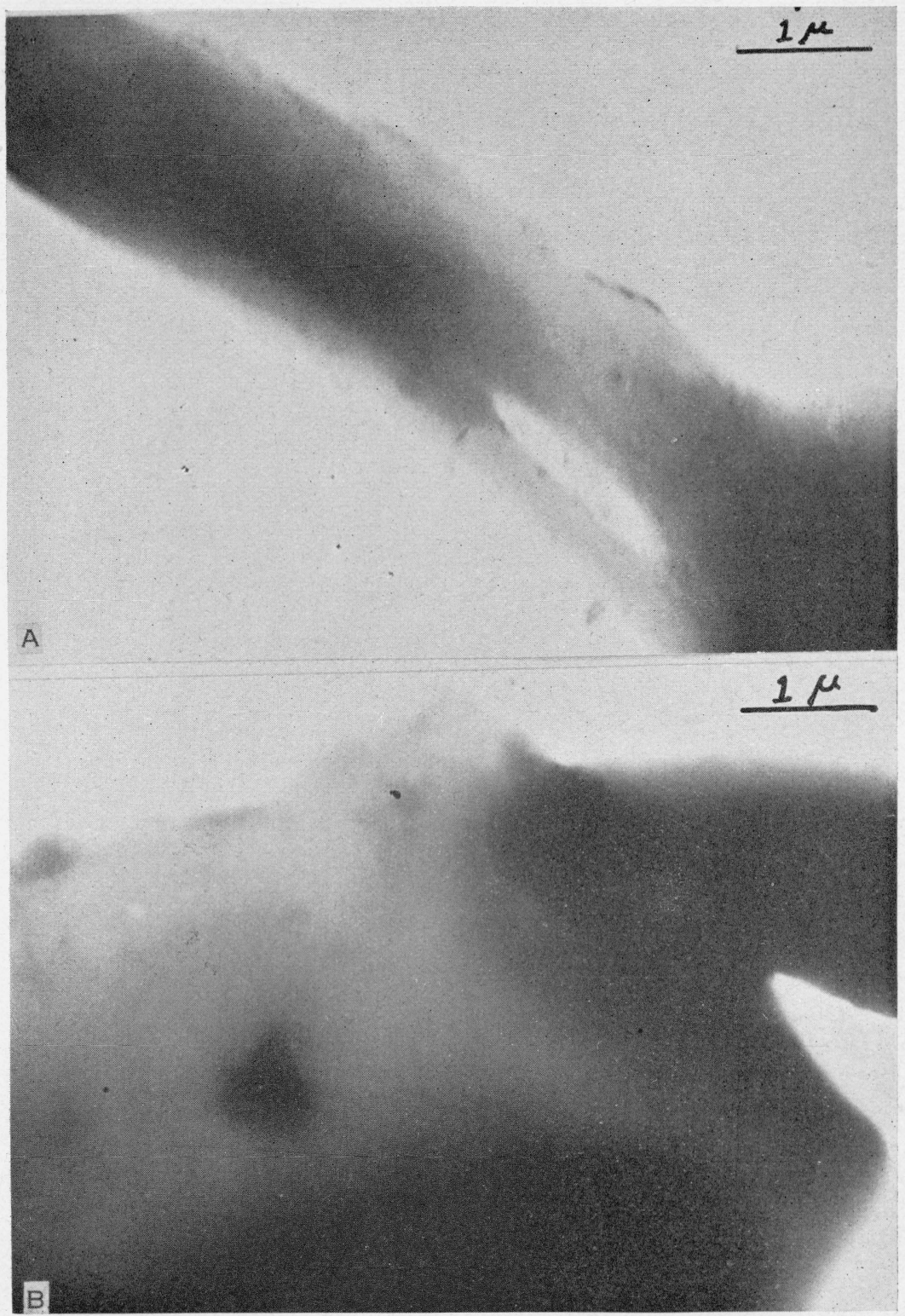

FIGURE 5.-Parts of scales removed mechanically from fibers.

$A$, Thin sliver of scale obtained from fiber by scraping. $B$, Piece of scale chipped off during passage of fiber through a Wiley mill. (The completely opaque parts of the micrograph are due to thick fragments of the cortex which cling to the scale.) Electron micrograph, $X 16,500$. 


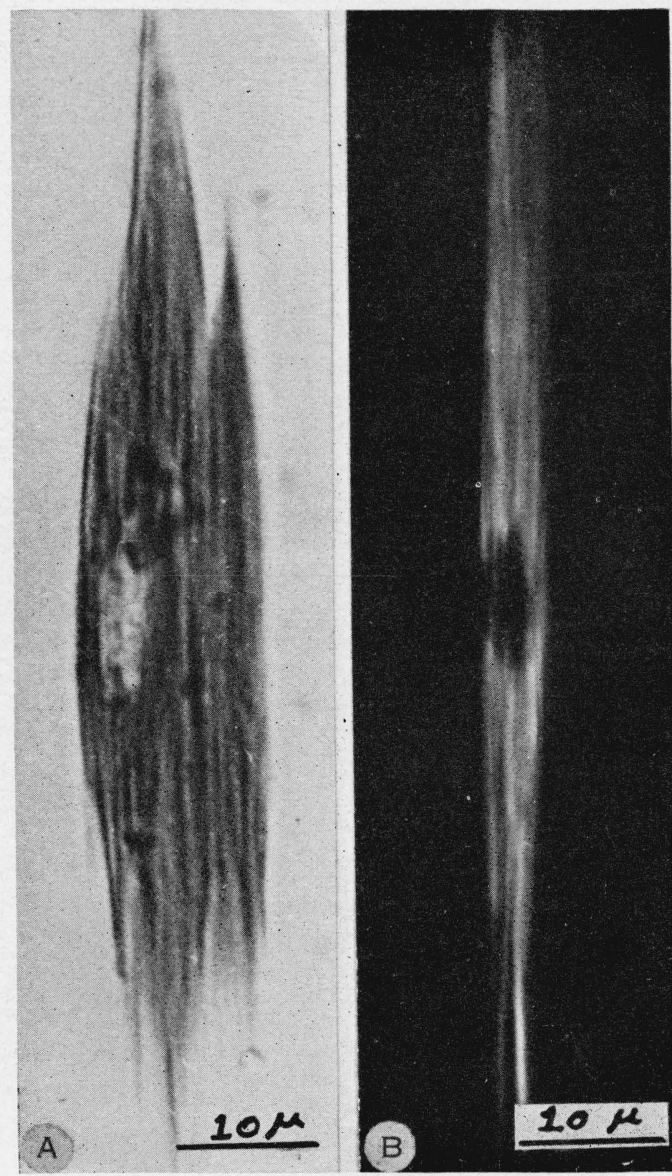

Figure 6.-Cortical cells from treated wool.

$A$, Single cell, showing the nucleus, and the fibrillate appearance of the rest of the cell. Stained with orange II. $B$, Single cell, between crossed nicols, showing the nonbirefringent nucleus in the birefringent cell. Photomicrograph, $\times 1,500$. 

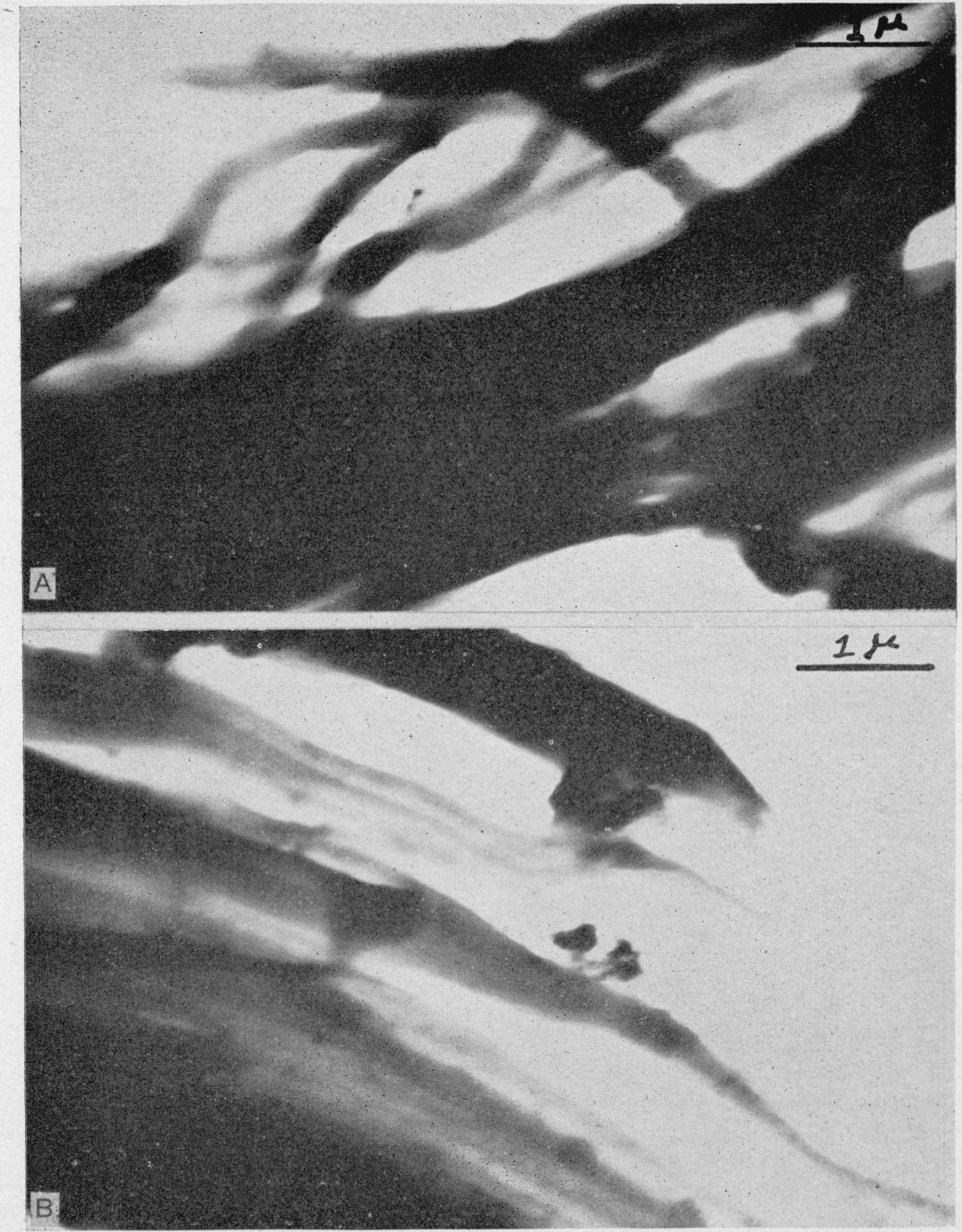

FIGURE 7.- $A$ and $B$ are parts of cortical cells from treated wool, showing separation of the fibrils into still smaller microfibrils.

Electron micrograph, $\times 16,000$. 


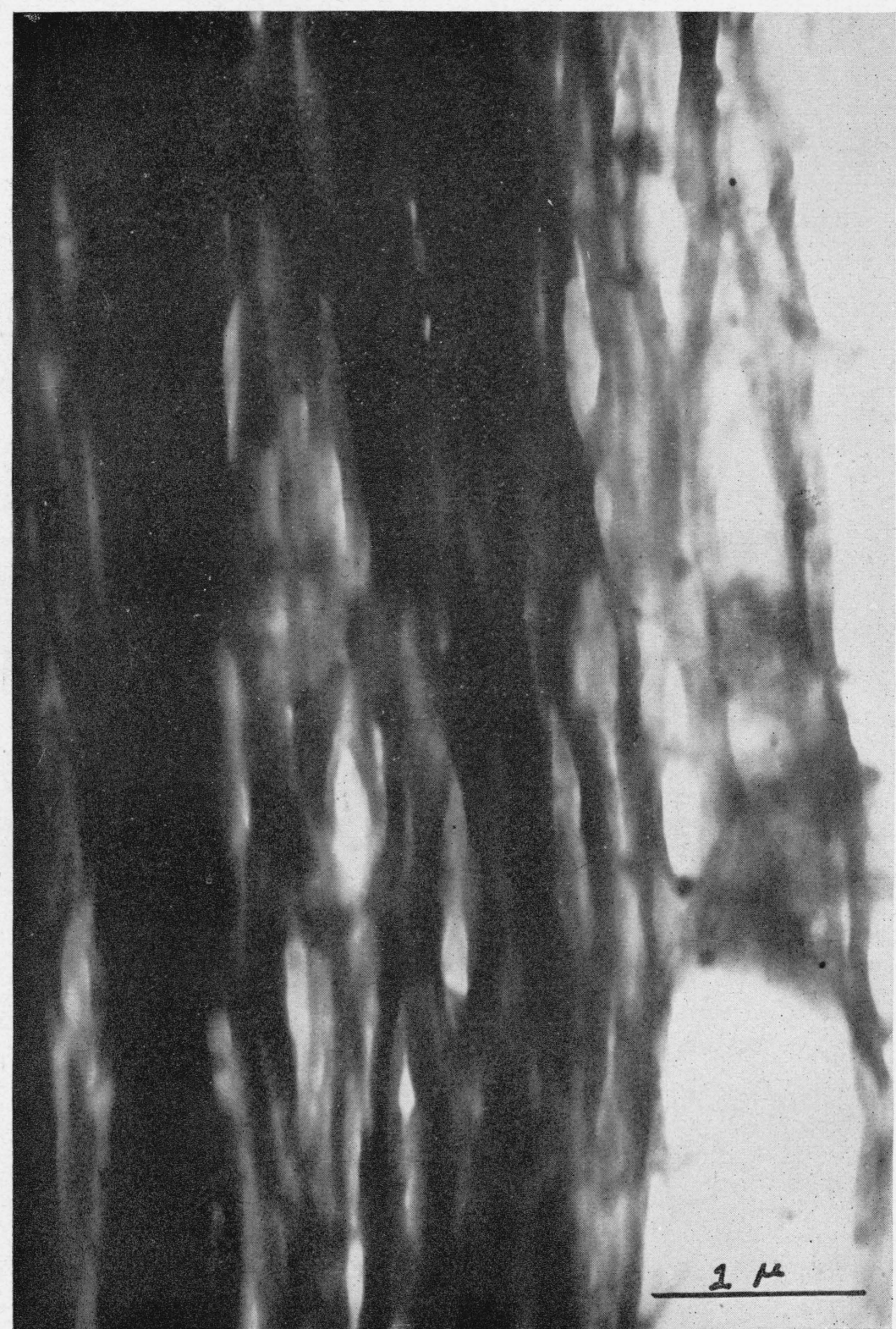

FIgURE 8.-Part of cortical cell, showing fibrils and microfibrils. Electron micrograph, $\times 26,500$. 


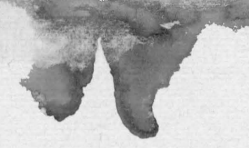

Journal of Research of the National Bureau of Standards

Research Paper 1561

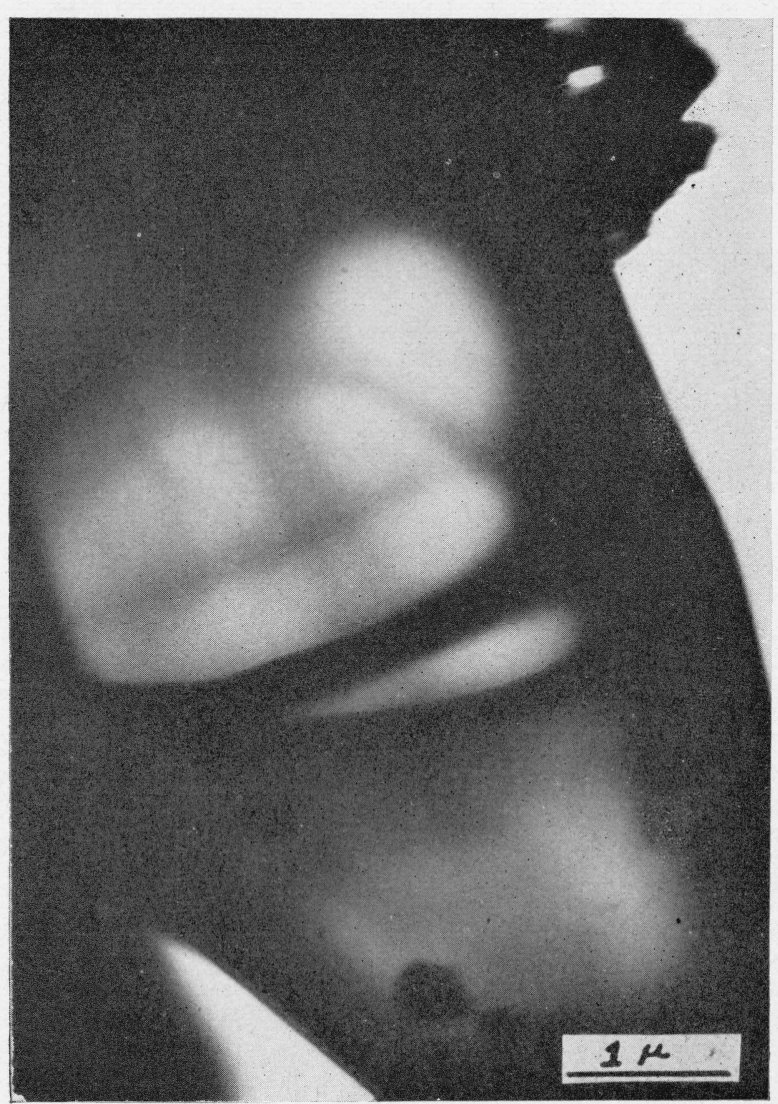

Figure 9.-Part of a cortical cell disorganized by the electrons. Electron micrograph, $\times 17,000$. 


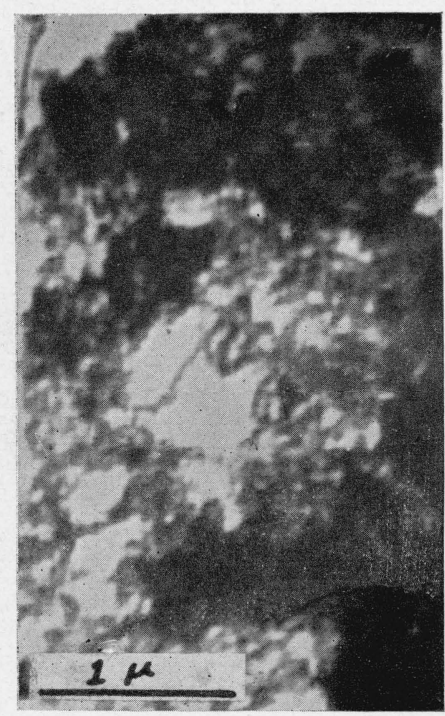

Figure 10.-Part of cortex obtained by mechanical action. Portion of a cell showing microfibrils. Electron micrograph, $\times 20,000$. 
materials [32], has been described previously in the cotton fiber $[33,34]$.

The differences in reaction of the cells from untreated and from treated wool to bombardment by electrons make it interesting to speculate on the causes of this phenomenon. Since the specimens of wool used in this phase of the work were identical except for the reduction and methylation treatment, it seems probable that this treatment may account for the observed behavior.

Because of the thickness and density of the cortical cells, it may be expected that under bombardment by the electrons a large amount of energy would be absorbed, and this in turn would tend to disorganize the keratin. The foamy appearance of the disorganized cells suggests, moreover, that the decomposition may be accompanied by the evolution of gases. Consequently, a certain degree of breakdown might be expected to occur in cells from both the untreated and from the treated wool. However, in untreated wool the close alignment of the keratin molecules presumably does not permit the gases to diffuse readily, and as a result the cell explodes. The looser arrangement of the molecular chains in reduced and methylated wool, on the other hand, apparently allows diffusion to take place more easily and consequently disintegration does not occur. Also, in preparing the treated wool the disulfide cross-linkages are ruptured (reduced) and then methylated to prevent their re-formation. This may impart to the long polypeptide chains more freedom of movement when subjected to mechanical forces. In untreated wool, on the other hand, the original cross-linkages remain intact and thereby hold the keratin chains in rather rigid alinement. ${ }^{4}$

Although both scale and cortical cells from untreated wool usually underwent disintegration by the electrons, occasionally scales from the former were not disorganized (compare figs. $4, A$, and $4, B$ ). In these instances, the specimens presumably were thin enough for the electrons to pass through without disturbing the molecular architecture of the cell.

Additional explanations for the differences in behavior of these samples of wool during bombardment may also be suggested. It is possible, for instance, that the treatment with pepsin removed from the reduced and methylated wool some substance, thereby increasing the porosity of the treated wool as compared with the untreated wool. This difference in porosity might account for the observed differences in reaction. Similarly, the temperature at which disintregation of the specimens occurs may be lower for untreated than for treated wool, and this may be another explanation of the phenomenon. However, regardless of the specific reasons for the unlike behavior of these specimens in the electron microscope it is instructive to note that besides the differences which these wool fibers show in alkalisolubility, in mechanical properties, and in susceptibility to attack by enzymes and microorganisms, there is also this additional difference in the reaction of their component cells when exposed to electrons.

Cortical material which had received no specific chemical treatments, but which was prepared by trituration as previously described, was also examined for comparison with the cells released from wool by chemical action. Again, it was found that the cortex is made up of a highly fibrous material. Because the sections were prepared by rather

${ }^{4}$ Stress-strain measurements indicate that reduced and methylated fibers are capable of greater elongation than untreated fibers [35]. 
drastic mechanical action, and also because the plane of the sections is uncertain, a detailed interpretation of the micrographs is difficult. However, figure 10 shows what appears to be innumerable interlocking and variously aggregated microfibrils, and thereby gives further evidence of the fibrous nature of the cortical cells.

There is abundant evidence from chemical, physical, and microscopic studies, in support of a fundamental fibrous structure of textile fibers, and to this knowledge the present investigation of wool gives additional support. Whereas with the optical microscope only fibrils may be observed within the cortical cells, the electron microscope resolves still finer microfibrils. It is important to note, however, that studies with the electron microscope support previous evidence which indicates that only the cortex and not the cuticle appears to have a fibrous structure.

\section{REFERENCES}

[1] C. Kronacher and G. Lodemann, Technik der Haar und Wolleuntersuchung, Berlin (1930).

[2] W. von Bergen, American Wool Handbook (American Wool Handbook Publishing Co., New York, N. Y., 1938.

[3] W. von Bergen and W. Kraus, Textile Fiber Atlas (American Wool Handbook Publishing Co., New York, N. Y., 1942).

[4] H. Reumuth, Klepzig's Textil-Z. 21, 352 and 34, 495 (1939).

[5] C. Müller, Zellforsch. Mikroskop. Anat. [A] $\mathbf{2 9 ,} 1$ (1939).

[6] C. W. Hock, R. C. Ramsey, and M. Harris, J. Research NBS 2\%, 181 (1941) RP1412; Am. Dyestuff Reptr. 30, 449 (1941).

[7] W. T. Astbury and H. J. Woods, Trans. Roy. Soc. (London) [A] 232, 333 (1933).

[8] W. T. Astbury and F. O. Bell, Nature 147, 696 (1941).

[9] J. B. Speakman, Proc. Roy. Soc. (London) [B] 103, 377 (1928).

[10] J. B. Speakman and F. Townend, Nature 139, 411 (1937).

[11] W. $\dot{I}$. Patterson, W. B. Geiger, L. R. Mizell, and M. Harris, J. Research NBS 2\%, 89 (1941) RP1405.

[12] W. B. Geiger, W. I. Patterson, L. R. Mizell, and M. Harris, J. Research NBS 27, 459 (1941) RP1433; Am. Dvestuff Reptr. 30, 659 (1941).

[13j J. B. Speakman, J. Soc. Chem. Ind. 50, 1 (1931).

[14] K. M. Rudall, Proc. Leeds Phil. Soc. (Sci. Sec.) 4, 13 (1941).

[15] J. B. Speakman and S. G. Smith, J. Soc. Dyers Colourists 5\%, 121 (1936).

[16] R. Haller and F. W. Holl, Kolloid, Z. "y5, 212 (1936).

[17] R. Haller, Melliland Textilber, 18, 5 (1937).

[18] G. L. Royer and H. E. Millson, Am. Dyestuff Reptr. 29, 697 (1940).

[19] R. Burgess and C. Rimington, J. Roy. Microscop. Soc. 49, 341 (1929).

[20] A. Herzog, Melliand Textilber. 12,678 (1931).

[21] H. Reumuth, Klepzig's Textile-Z. 21, 352 (1939).

[22] Allwörden, Z. angew. Chem. 29, 77 (1916).

[23] P. G. Unna and L. Golodetz, Monatsh. prakt. Dermatologie 44, 398 and 459 (1907).

[24] S. R. Trotman, E. R. Trotman, and R. W. Sutton, J. Soc. Chem. Ind. 45 T, 20 (1926).

[25] J. G. Bekker and A. T.King, Biochem. J. 25, 1077 (1931).

[26] M. von Ardenne, Elektronen Ưbermikroskopie (Julius Springer, Berling, 1940).

[27] E. F. Burton and W. H. Kohl, The Electron Microscope, (Reinhold Publishing Co., New York, N. Y., 1942).

[28] A. T. King, Biochem. J. 21, 434 (1927).

[29] W. T. Astbury and A. Street, Trans, Roy. Soc. (London) [A] 2380, 333 (1931).

[30] H. Zahn, Melliand Textilber. 21, 505 (1940).

[31] H. Zahn, 22, 305 (1941).

[32] A. G. Richards and T. F. Anderson, J. Morphology 71,135 (1942).

[33] H. Mahl, Kolloid Z. 96, 7 (1941).

[34] R. B. Barnes and C. J. Burton, Am. Dyestuff Reptr. 31, 254 (1942).

[35] M. Harris, L. R. Mizell, and L. Fourt, J. Research NBS 29, 73 (1942) RP1486.

Washington, August 9, 1943. 